\title{
Influence of Packaging Material on Bread Characteristics during Ageing
}

\author{
By M. Ambrogina Pagani,* Mara Lucisano, Manuela Mariotti and Sara Limbo \\ Dipartimento di Scienze e Tecnologie Alimentari e Microbiologiche (DiSTAM), University of Milan, Via G. Celoria 2, \\ I-20I33 Milan, Italy
}

One of the priorities of today's bread-making industry is to find suitable packaging solutions to satisfy the peculiar requirements of bread, mostly appreciated by Italian consumers for its crispy crust. The packaging material should allow for both rapid heat exchange with the environment and water vapour evaporation to prevent condensation inside the package. Perforated orientated polypropylene (OPP) films are currently the best materials available for satisfying the industry's requirements. Recently, our group demonstrated that bread wrapping with perforated films is efficacious against bread contamination. The aim of this work was to verify whether these types of films could also influence the trend of phenomena related to product ageing. In particular, variations in the moisture inside the loaf during storage and their influence on changes in crumb softness were investigated. Three OPP films and one double-layer film bag with different hole size characteristics were chosen for this study and their performances were compared with those of a paper bag. Because of the considerable differences in the hole size characteristics, the films showed very different barrier effects to water evaporation. The C250 OPP film (hole mean diameter $=0.54 \mathrm{~mm}$ and density $=$ 21.4 holes $/ \mathrm{cm}^{2}$ ) played an interesting role in modulating moisture variations.

Wrapping bread in this film enabled both crust crispness and crumb softness to be maintained during $48 \mathrm{~h}$ of storage. Such performances cannot effectively be obtained by using alternative industrial bread packaging materials, such as paper bags.

Copyright (C) 2006 John Wiley \& Sons, Ltd.

Received 28 November 2004; Revised 14 October 2005; Accepted 27 January 2006

KEY WORDS: bread; packaging material; crumb moisture; bread ageing

\section{INTRODUCTION}

Although industrial bread production only became established in Italy in the 1990s, in 2002 it reached 4100 tons, about $10 \%$ of the market share (Federazione Italiana Panificatori, personal communication), and is steadily growing. A fair price: quality ratio accounts for the increasing interest in the industrial product. The industrial production process, although using similar operations to those of the artisan process, is associated with higher productivity, and the relevant market distribution channels (usually organized retailing and distribution industry) make it possible to obtain good quality characteristics of the product at lower costs. Nowadays, one of the priorities of the Italian bread-making industry is to find suitable packaging solutions to satisfy the peculiar requirements

* Correspondence to: M. A. Pagani, DISTAM, University of Milan,

Via G. Celoria 2, I-20133 Milan, Italy.

E-mail: ambrogina.pagani@unimi.it 


\section{and Science}

of bread, which is widely appreciated by Italian consumers for its crispy crust, generally $2-3 \mathrm{~mm}$ thick. ${ }^{1}$ Bread packaging in modified atmospheres using nitrogen and/or carbon dioxide can be efficacious in the extension of the microbial shelf-life of the product. The removal of oxygen from the headspace of packages inhibits the growth of aerobic microrganisms. ${ }^{2}$ In contrast, a positive effect of modified atmospheres on the physicochemical changes occurring during bread ageing is questionable, because the product firming rate and the kinetics of starch retrogradation are comparable to those of bread stored in atmospheric air. ${ }^{3}$ In industrial processes, bread is mainly packed at the oven outlet at a temperature of $80-90^{\circ} \mathrm{C}$, so the packaging material should allow for both rapid heat-exchange with the environment and water vapour evaporation to prevent condensation from forming inside the package: the latter conditions would not only bring about an ideal microclimate for the growth of moulds but also result in early crust softening, which would make the product unacceptable. ${ }^{4}$

Perforated orientated polypropylene (OPP) films are currently the best materials for meeting industrial requirements. Perforations and pinholes can be considered as a valid tool for controlling the atmosphere and relative humidity of the packaged products by increasing the rates of moisture exchanges from the warm loaf ${ }^{5}$ to the environment. At the same time, pinholes are effective against the risk of physical contamination of the bread. ${ }^{6}$ The alternative packaging material to perforated films is the paper bag, which guarantees gas-exchange with the environment, thanks to the high permeability of the material, and enables the appearance of the product to be easily verified through a cellophane window.

The aim of this work, in which characterization of some materials investigated by Piergiovanni et $a l{ }^{6}$ was completed, was to verify whether bread wrappings with perforated films could not only effectively protect this food product from contamination but also influence the trend of a number of phenomena related to bread ageing. In particular, variations in the moisture inside the loaf during storage for times reflecting its commercial shelf-life were evaluated. How such variations may affect indices for crumb softness was also investigated.

\section{MATERIALS AND METHODS}

\section{Bread-making trials}

A commercial wheat flour (protein, 12.2\% db; alveographic $\mathrm{W}, 220 \times 10^{-4} \mathrm{~J}$; farinographic stability, $6.5 \mathrm{~min}$ ) was used for the bread-making. Breadmaking trials (24 trials over 4 weeks) were carried out according to the AACC straight-dough procedure. ${ }^{7}$ For every trial, $200 \mathrm{~g}$ flour was used and two loaves were produced. The weight and the volume of the loaves, evaluated by rapeseed displacement, were determined $30 \mathrm{~min}$ after baking. After packaging, the bread was stored under controlled moisture and temperature conditions $\left[20^{\circ} \mathrm{C}, 60 \%\right.$ relative humidity (RH)] for $48 \mathrm{~h}$ and analysed after 2, 19, 26 and $48 \mathrm{~h}\left(T_{1}, T_{2}, T_{3}\right.$ and $T_{4}$, respectively) after packaging.

\section{Packaging materials}

In order to describe the conditions applied during the industrial process, hot bread samples were wrapped in $20 \times 20 \mathrm{~cm}$ bags, which were subsequently sealed. Three perforated OPP films were used (Table 1). Different hole size characteristics resulted in different open surfaces. For the PY85 film, which is characterized by an open surface higher than $12 \%$, a double-layer film bag (PY85d) was also prepared.

The water vapour permeability (water vapour transmission rate, or WVTR) of each film was evaluated by the ASTM E-96 'Dish method' at $25^{\circ} \mathrm{C}$ and $67 \%$ RH. ${ }^{8}$ The cup mouth, which was filled with a desiccant $\left(\mathrm{CaCl}_{2}\right)$, was hermetically sealed using a circular film specimen. The cup was then subjected to a pre-established temperature and relative humidity conditions and weighed at given time intervals to determine water absorption by the desiccant and to obtain the WVTR index from the following equation:

$$
\text { WVTR }=G A^{-1} t^{-1}
$$

where $G=$ weight change of the desiccant, $g$; $A=$ test area (cup mouth area) and $\mathrm{m}^{2} ; t=$ time (24h).

Another packaging material tested was the socalled 'paper bag' (PB), i.e. a parallel composite 


\begin{tabular}{|c|c|c|c|c|c|}
\hline Sample & $\begin{array}{l}\text { Film } \\
\text { thickness } \\
(\mathrm{mm})\end{array}$ & $\begin{array}{l}\text { Hole mean } \\
\text { diameter } \\
(\mathrm{mm})\end{array}$ & $\begin{array}{l}\text { Hole mean } \\
\text { surface } \\
\left(\mathrm{mm}^{2}\right)\end{array}$ & $\begin{array}{l}\text { Density } \\
\text { (holes/cm) }\end{array}$ & $\begin{array}{l}\text { Open } \\
\text { surface } \\
(\%)\end{array}$ \\
\hline $\mathrm{ClO}$ & 15 & $0.44 \pm 0.08^{\mathrm{a}}$ & 0.15 & 0.9 & $0.14 \pm 0.01^{a}$ \\
\hline C250 & 15 & $0.54 \pm 0.02^{b}$ & 0.23 & 21.4 & $4.96 \pm 0.09^{b}$ \\
\hline PY85 & 12 & $1.35 \pm 0.03^{c}$ & 1.43 & 8.6 & $12.25 \pm 0.05^{c}$ \\
\hline
\end{tabular}
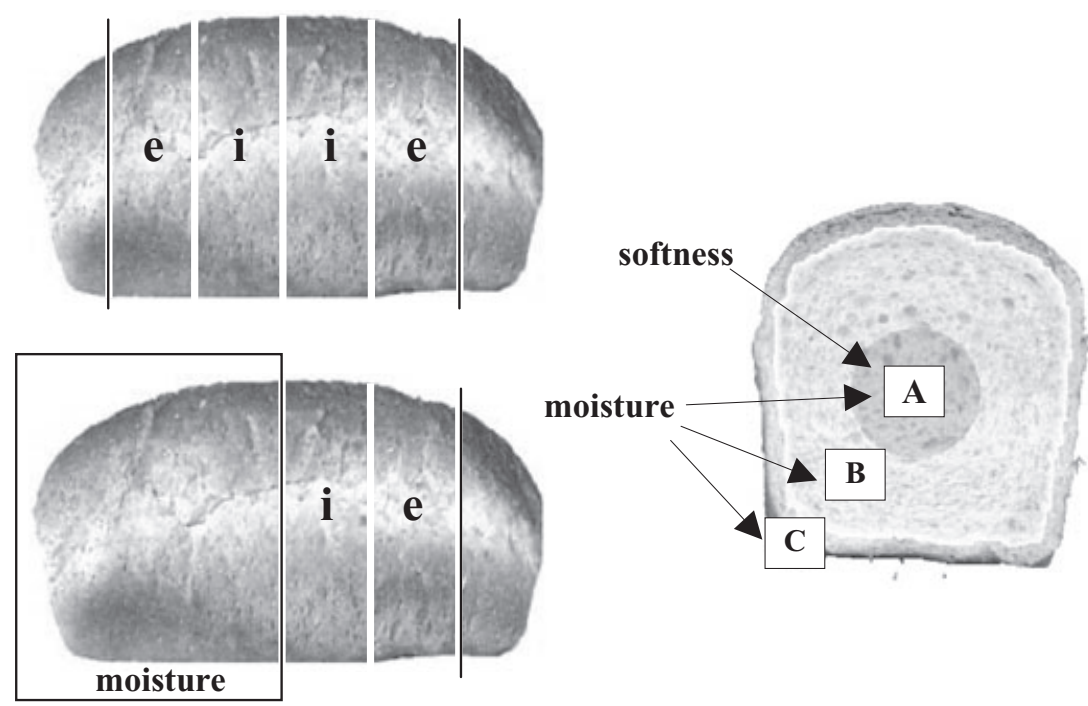

Figure I. Bread sampling for analyses.

structure, whose surface is made of paper (88\%) and a cellophane window in the remaining portion.

\section{Sampling and characterization of bread}

Two bread loaves were analysed for each storage time. Four $22 \mathrm{~mm}$ thick slices were obtained from the first loaf after removal of both ends (about $10 \mathrm{~mm}$ in thickness) (Figure 1). The second loaf was cut in half and two slices were obtained, as shown in Figure 1. Altogether, three slices came from the external region (slices ' $\mathrm{e}$ ') and three from the internal region (slices ' $i$ ') of the bread. The remaining half portion of the second loaf was ground to obtain samples to determine the total moisture of bread. ${ }^{9}$ In order to follow the distribution of moisture along the radius of the bread, three specimen types, designated as A, B and C and represented in Figure 1, were obtained from each slice of bread. Specimen A was obtained from the slice core by a special metal extruder $27 \mathrm{~mm}$ in diameter. Specimen $C$, obtained from the slice edge, corresponded to the crust. The part of crumb included between region $\mathrm{A}$ and $\mathrm{C}$ represented specimen $\mathrm{B}$. 


\section{and Science}

Crumb softness was determined on specimens A by a compression test performed using an Instron Universal Testing Machine, Model 4301, dynamometer at a deformation speed of $20 \mathrm{~mm} / \mathrm{min}$, using a $100 \mathrm{~N}$ load cell. Young's modulus (YM) and load at 30\% deformation (L30\%) were calculated for each result.

\section{Statistical analysis}

Analytical results were processed by STATGRAPHIC ${ }^{\circledR}$ Plus for Windows 4.0. Analysis of variance (ANOVA) was performed using LSD test to compare sample means; differences were considered significant at $p<0.05$.

\section{RESULTS AND DISCUSSION}

\section{Repeatability of bread-making trials}

The 48 loaves obtained during 24 bread-making trials showed a mean volume of $730 \mathrm{ml}$ and a mean weight of $141.9 \mathrm{~g}$ (Table 2). Both parameters were characterized by low coefficient of variation $(<2.5 \%)$, indicating high repeatability of the breadmaking process. Homogeneity among bread samples was also demonstrated by a low moisture standard deviation at time $T_{1}$ (Table 2). Each loaf presented an evident crust, about $2 \mathrm{~mm}$ in thickness, and a high specific volume, a parameter that is positively correlated to bread softness. ${ }^{10}$

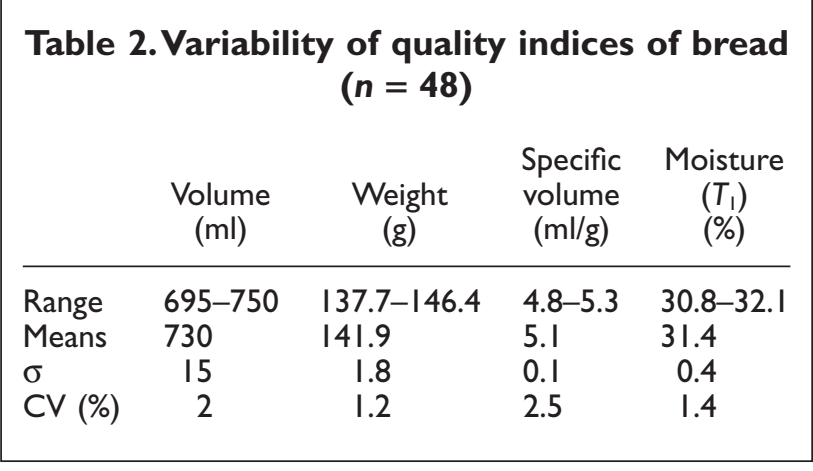

\section{Distribution of moisture inside bread along its longitudinal axis}

Before investigating the influence of different packaging materials on the bread ageing phenomena, the uniformity of moisture distribution was evaluated along the longitudinal axis of the product to avoid distinguishing between samples obtained from internal and external slices of the loaf. This evaluation was performed on bread without wrapping, i.e. under conditions associated with rapid moisture exchanges between product and environment, using two loaves at each storage time. Moisture was checked in all regions (i.e. specimens A, B and C) of each slice (Figure 2). No statistically significant differences $(p<0.05)$ were noted among the moisture values obtained from the internal slices (slices ' $i$ ') and those obtained from the external slices (slices 'e') for both crumb (areas A and B) and crust regions (area C) at any storage time considered. As a result, the following evaluations of bread were performed regardless of the sample position along the longitudinal axis of bread.

\section{Properties of perforated films}

Previous research on the characterization of perforated OPP films ${ }^{6}$ shows a significant relationship between the geometrical characteristics of film holes (i.e. density, hole average surface, open surface) and the risk of bread contamination by polluting materials, such as saliva and sweat deriving from improper product handling. The geometrical characteristics of the holes of most films tested were able to guarantee a high protection against the above-mentioned contamination. In order to better understand the effect that OPP films may have on spontaneous phenomena causing bread ageing, three films with differing hole size characteristics (Table 1) were chosen. The C250 designated material showed a hole mean surface $\left(s_{\mathrm{m}}\right)$ and open surface within the recommended range limit to $5 \%$ the risk of contamination $\left(s_{\mathrm{m}}<0.3 \mathrm{~mm}^{2}\right.$; open surface $<5 \%$; Piergiovanni, personal communication) and may hence be considered a hygienically suitable material for bread packaging. In addition to this material, two films were taken into account, which, for their hole size 


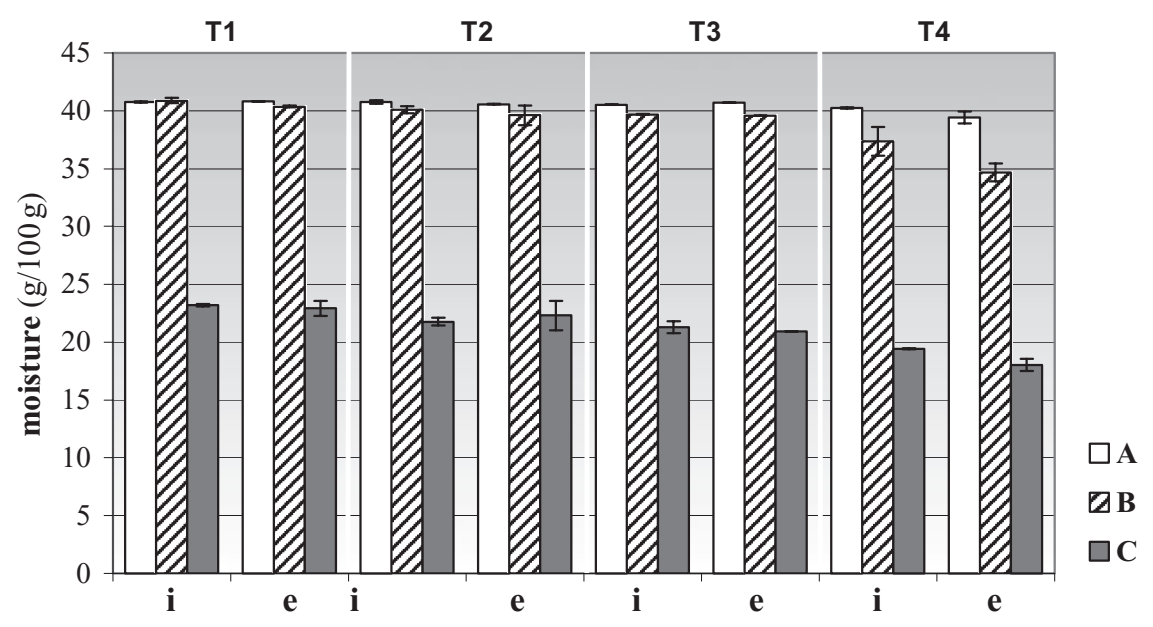

Figure 2. Bread moisture distribution at different storage times in the three bread areas considered. $A$, the slice core; $B$, the crumb included between regions $A$ and $C$; $C$, the slice edge, corresponding to the crust; e, external slices; i, internal slices.

and density per surface unit, were sited at both ends of the ranges detected for these parameters. The C10 film showed very small holes and 0.1\% open surface, while the size characteristics of the material designated PY85 exceeded the recommended limits to minimize the risk of contamination. For this reason, this material was also tested as a double-layer film (PY85d) in order to reduce the open surface as compared to the single-layer film. Performance of the films was compared with those of the paper bag (PB), which is a material characterized by a very high index for vapour transmission.

As a result of the wide range in hole size characteristics, the films had very different barrier effects to water evaporation at the product's surface. This phenomenon is graphically represented by the straight lines reported in Figure 3, whose slope allowed the WVTR index to be evaluated. In particular, the WVTR value for the C10 film, due to its limited open surface, was definitely lower than that determined for the other films. The PY85 single-layer film had the highest WVTR value of $587 \mathrm{~g} / \mathrm{m}^{2} / 24 \mathrm{~h}$. When this material was used as a double-layer film (PY85d), water vapour transmission decreased by approximately $40 \%$, resulting in very similar values to those obtained with the C250 film.

\section{Influence of perforated film on bread moisture during storage}

A progressive dehydration took place in all samples over $48 \mathrm{~h}$, albeit with differing severity. Significant differences for moisture values among bread samples were detected from $T_{3}$, as can be seen in Figure 4. Bread packaging using the perforated PY85 film, where high transpiration of the product occurred, was associated with a considerable moisture loss, as high as $25 \%$ of the initial moisture during $48 \mathrm{~h}$ storage. The opposite behaviour was observed for bread wrapped in the C10 film, characterized by a very low WVTR value $\left(76.4 \mathrm{~g} / \mathrm{m}^{2} / 24 \mathrm{~h}\right)$. In this case, moisture loss as low as $10 \%$ was detected for bread over the same time interval. Intermediate moisture loss of $17-20 \%$ was observed for bread wrapped in double-layer PY85 film, C250 film and paper bag.

Evolution of moisture in the three regions of bread slices is shown in Figure 5 and Table 3. The trend of bread wrapped in the PY85 film (single 


\section{Packaging Technology}

\section{and Science}

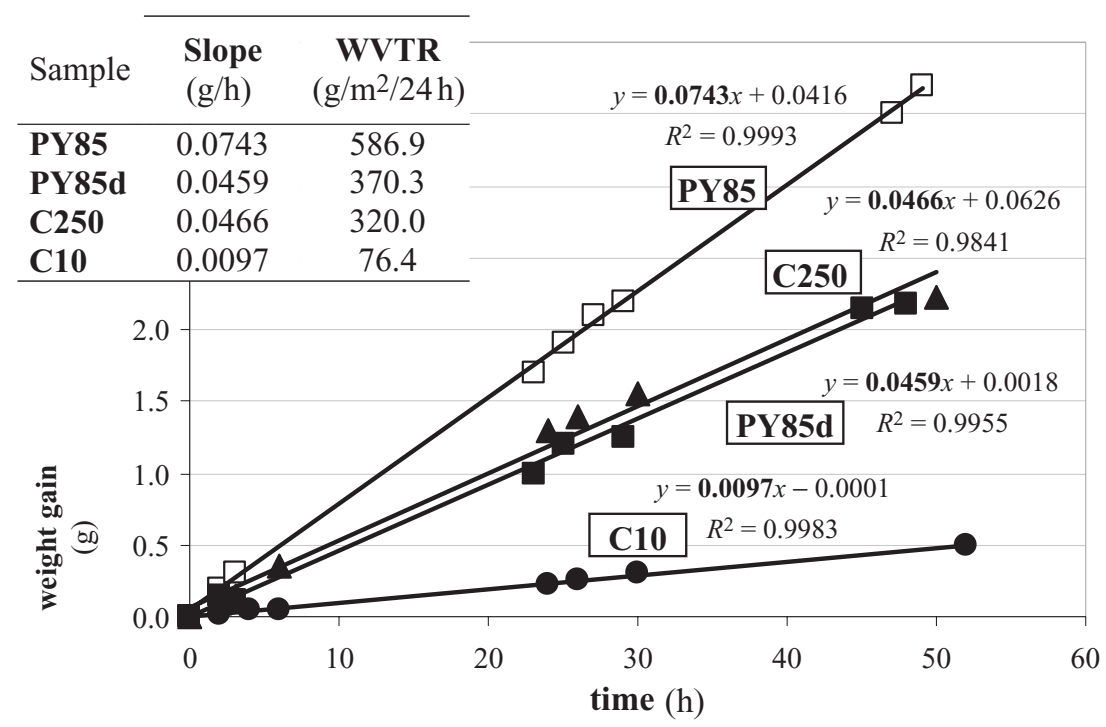

Figure 3. Desiccant weight change and water vapour transmission rate (WVTR) of perforated films.

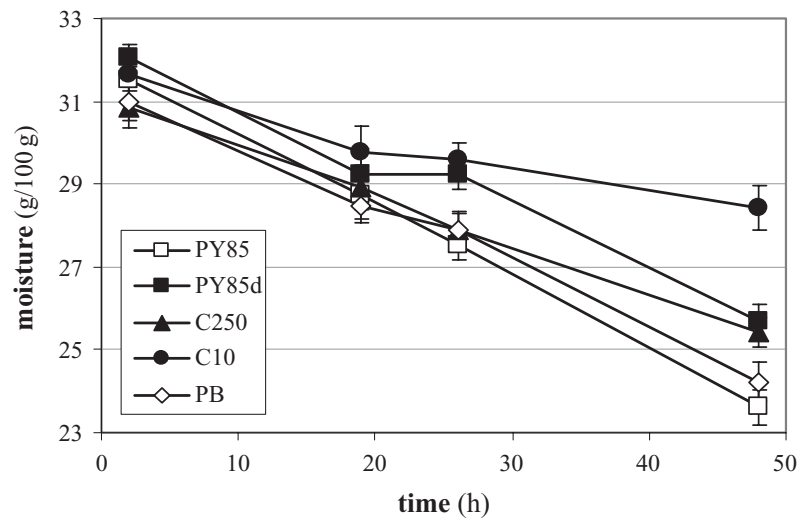

Figure 4. Moisture changes in loaves wrapped with different materials during storage. $A$, the slice core; $B$, the crumb included between regions $A$ and $C ; C$, the slice edge, corresponding to the crust.

layer) was comparable to that of the sample wrapped in the paper bag. The high open surface of the perforated film allowed rapid water redistribution and evaporation, as naturally occurs in bread wrapped in a very permeable material, such as paper.

At the end of storage (time $T_{4}$ ), the crumb moisture (regions A and B) showed no differences according to the wrapping film (Table 3). On the

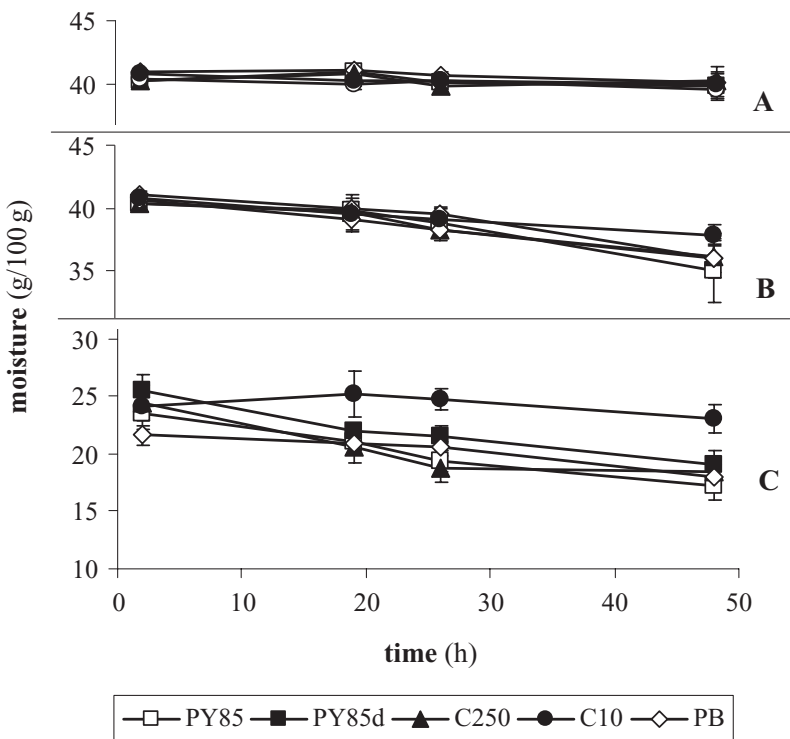

Figure 5. Evolution of moisture in the three regions of bread slices during storage.

contrary, the crust (region C) was characterized by significantly lower moisture values for loaves wrapped in C250 and PY85 (both single and double layer), thus indicating that the crispness characteristics had been better maintained. 


\begin{tabular}{|c|c|c|c|c|}
\hline Film & $T_{1}$ & $T_{2}$ & $T_{3}$ & $T_{4}$ \\
\hline $\begin{array}{l}\text { Crumb- - } \\
\text { C } 10 \\
\text { C } 250 \\
\text { PY } 85 \\
\text { PY } 85 d \\
\text { PB }\end{array}$ & $\begin{array}{l}\text { gion A } \\
40.89^{\mathrm{ab}} \\
40.28^{\mathrm{a}} \\
40.27^{\mathrm{a}} \\
41.75^{\mathrm{b}} \\
40.53^{\mathrm{a}}\end{array}$ & $\begin{array}{l}40.31^{\mathrm{ab}} \\
40.87^{\mathrm{b}} \\
41.00^{\mathrm{b}} \\
40.65^{\mathrm{ab}} \\
40.10^{\mathrm{ab}}\end{array}$ & $\begin{array}{l}40.12^{\mathrm{a}} \\
40.36^{\mathrm{a}} \\
39.97^{\mathrm{a}} \\
40.13^{\mathrm{a}} \\
39.66^{\mathrm{a}}\end{array}$ & $\begin{array}{l}40.66^{\mathrm{a}} \\
40.36^{\mathrm{a}} \\
40.36^{\mathrm{a}} \\
40.13^{\mathrm{a}} \\
39.66^{\mathrm{a}}\end{array}$ \\
\hline $\begin{array}{l}\text { Crumb - } \\
\text { C } 10 \\
\text { C } 250 \\
\text { PY } 85 \\
\text { PY 85d } \\
\text { PB }\end{array}$ & $\begin{array}{c}\text { gion B } \\
40.82^{\mathrm{b}} \\
40.38^{\mathrm{a}} \\
40.35^{\mathrm{a}} \\
41.08^{\mathrm{c}} \\
40.58^{\mathrm{a}}\end{array}$ & $\begin{array}{l}39.56^{\mathrm{a}} \\
39.66^{\mathrm{a}} \\
39.87^{\mathrm{a}} \\
39.32^{\mathrm{a}} \\
39.08^{\mathrm{a}}\end{array}$ & $\begin{array}{l}38.09^{\mathrm{a}} \\
38.19^{\mathrm{a}} \\
38.76^{\mathrm{a}} \\
38.93^{\mathrm{a}} \\
38.26^{\mathrm{a}}\end{array}$ & $\begin{array}{l}37.83^{\mathrm{a}} \\
36.19^{\mathrm{a}} \\
34.95^{\mathrm{a}} \\
36.03^{\mathrm{a}} \\
35.97^{\mathrm{a}}\end{array}$ \\
\hline $\begin{array}{l}\text { Crust - } \\
\text { C } 10 \\
\text { C } 250 \\
\text { PY } 85 \\
\text { PY 85d } \\
\text { PB }\end{array}$ & $\begin{array}{l}\text { ion } C \\
24.12^{\text {bc }} \\
24.39^{\text {bc }} \\
23.46^{\mathrm{b}} \\
25.53^{\mathrm{c}} \\
21.61^{\mathrm{a}}\end{array}$ & $\begin{array}{l}25.18^{\mathrm{b}} \\
20.61^{\mathrm{a}} \\
20.99^{\mathrm{a}} \\
21.92^{\mathrm{a}} \\
20.84^{\mathrm{a}}\end{array}$ & $\begin{array}{l}23.06^{\mathrm{c}} \\
18.5 \mathrm{I}^{\mathrm{b}} \\
17.16^{\mathrm{a}} \\
19.0 \mathrm{I}^{\mathrm{b}} \\
17.94^{\mathrm{ab}}\end{array}$ & $\begin{array}{l}23.04^{\mathrm{c}} \\
18.51^{\mathrm{a}} \\
17.16^{\mathrm{a}} \\
18.85^{\mathrm{a}} \\
20.66^{\mathrm{b}}\end{array}$ \\
\hline
\end{tabular}

For each region, mean values followed by the same letter are not significantly different within the same column $(p<0.05)$.

Different behaviour was observed for the sample stored in the perforated C10 film, which has an open surface as low as $0.14 \%$ of the total surface. In region A (Table 3), the crumb showed the initial moisture content throughout the storage period, whereas the crust was considerably wetter than that of bread wrapped in other materials. This event could already be detected at time $T_{2}(19 \mathrm{~h})$, and at time $T_{4}(48 \mathrm{~h})$ it caused specimen $C$ to have a moisture content only $1 \%$ lower than the initial content.

\section{Influence of perforated film on bread texture}

Given the alveolar structure of bread, the mechanical properties of the crumb and hence its texture were described by characterizing the relationships between stress and strain during compression by an elastic module, i.e. Young's modulus (YM) and load at $30 \%$ deformation $(L 30 \%)$. This last index was able to better describe the resistance of the
Table 4. Softness indices of crumb of wrapped bread at different storage times

\begin{tabular}{|c|c|c|c|c|}
\hline Film & $T_{1}$ & $T_{2}$ & $T_{3}$ & $T_{4}$ \\
\hline \multicolumn{5}{|c|}{ Young's modulus } \\
\hline C 10 & $7.0^{\mathrm{b}}$ & $27.1^{\mathrm{ab}}$ & $30.1^{a b}$ & $45.0^{b}$ \\
\hline C 250 & $5.0^{\mathrm{a}}$ & $23.4^{\mathrm{ab}}$ & $26.2^{\mathrm{ab}}$ & $32.5^{\mathrm{a}}$ \\
\hline PY 85 & $5.0^{\mathrm{a}}$ & $23.8^{\mathrm{ab}}$ & $31.2^{b}$ & $46.0^{b}$ \\
\hline PY 85d & $4.5^{\mathrm{a}}$ & $22.3^{\mathrm{a}}$ & $28.5^{\mathrm{ab}}$ & $43.1^{b}$ \\
\hline PB & $6.9^{b}$ & $25.7^{\mathrm{ab}}$ & $32.9^{b}$ & $42.5^{b}$ \\
\hline \multicolumn{5}{|l|}{ Load } \\
\hline C 10 & $0.55^{\mathrm{b}}$ & $1.63^{\mathrm{b}}$ & $2.17^{\mathrm{b}}$ & $2.45^{c}$ \\
\hline C 250 & $0.47^{\mathrm{a}}$ & $1.47^{\mathrm{a}}$ & $1.82^{\mathrm{a}}$ & $2.35^{\mathrm{ab}}$ \\
\hline PY 85 & $0.44^{\mathrm{a}}$ & $1.42^{\mathrm{a}}$ & $1.82^{\mathrm{a}}$ & $2.24^{\mathrm{ab}}$ \\
\hline PY 85d & $0.42^{\mathrm{a}}$ & $1.42^{\mathrm{a}}$ & $1.79^{a}$ & $2.37^{\mathrm{ab}}$ \\
\hline PB & $0.58^{b}$ & $1.70^{\mathrm{b}}$ & $2.17^{b}$ & $2.63^{b c}$ \\
\hline
\end{tabular}

Mean values followed by the same letter are not significantly different within the same column $(p<0.05)$.

crumb to large deformations similar to those obtained when chewing.

Compression tests were only carried out on cylindrical specimens obtained from the core of each slice (area A), a bread region characterized by regular cell development, to minimize any sample variation that was not associated with either ageing or packaging.

The reference loaf wrapped in a paper bag (PB) was characterized by a $Y M$ value of $6.9 \pm 0.6 \mathrm{kPa}$ and a $L 30 \%$ value of $0.58 \pm 0.04 \mathrm{~N}$ at time $T_{1}(2 \mathrm{~h})$ (Table 4$)$. These indices were not significantly different from those found for bread wrapped in C10 film at the same time interval $(Y M=7.0 \pm 0.4 \mathrm{kPa}$; $L 30 \%=0.55 \pm 0.03 \mathrm{~N})$. Conversely, significantly higher softness (i.e. lower $Y M$ and $L 30 \%$ values) was observed in samples wrapped in PY85 films $(P Y 85, Y M=5.0 \pm 0.6 \mathrm{kPa} ; L 30 \%=0.44 \pm 0.03 \mathrm{~N}$; PY86d, YM = $4.5 \pm 0.4 \mathrm{kPa} ; L 30 \%=0.42 \pm 0.04 \mathrm{~N}$ ) and C250 films $(Y M=5.0 \pm 0.7 \mathrm{kPa} ; L 30 \%=0.47 \pm$ $0.04 N)$. Subsequent storage times were characterized by progressive crumb hardening (Figure 6). The increase in crumb hardness, a complex phenomenon which has been related to moisture loss in other studies, ${ }^{10}$ was not shown to be associated with moisture variations of the crumb in the bread core at the time interval considered. Crumb hardness of bread wrapped in film C10 was unexpect- 


\section{and Science}
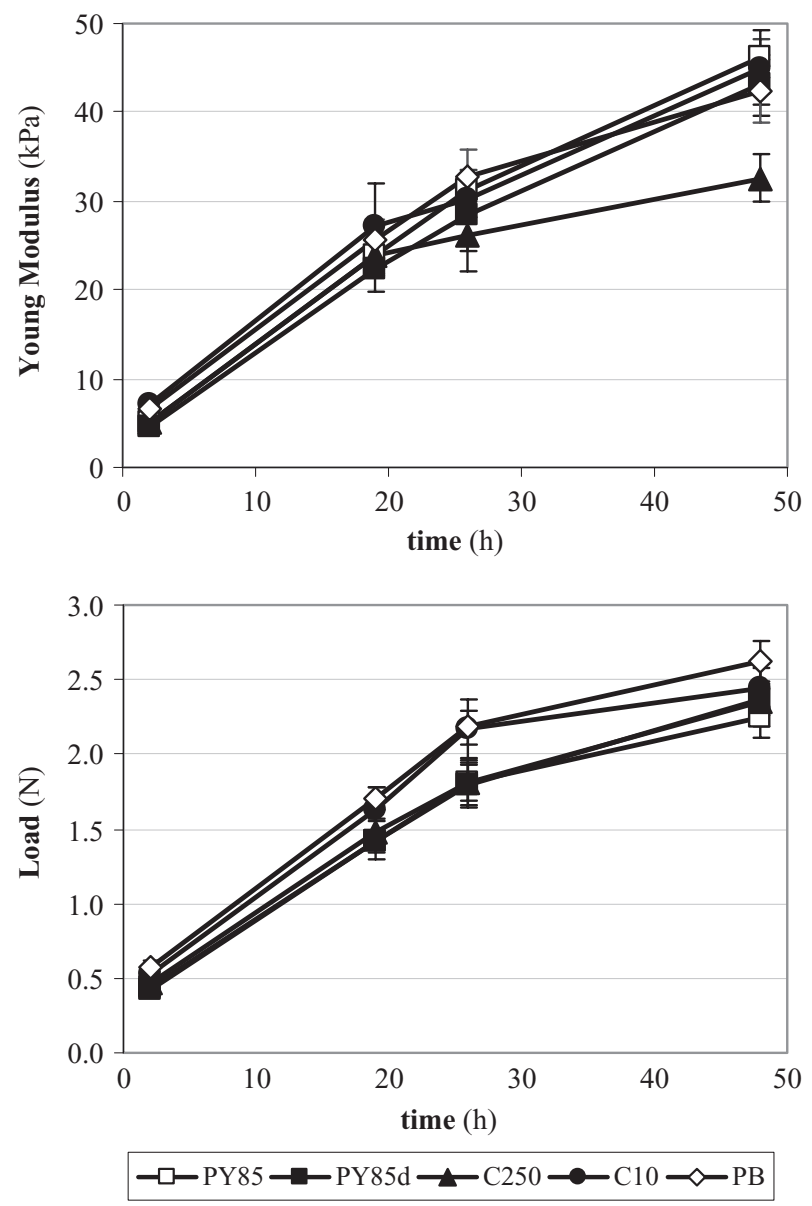

Figure 6. Rheological parameters of the central region of bread during storage.

edly high. Although this sample was characterized by a high moisture content in region $\mathrm{A}$ at all storage times, the $Y M$ value at time $T_{4}$ was not significantly different from that obtained from samples stored in materials with high water vapour permeability, such as paper bags and PY85 films. Significantly lower $Y M$ values over $48 \mathrm{~h}$ were only found for bread wrapped in C250 films starting from $T_{2}$. This film, characterized by adequate water vapour permeability, allowed both crust crispness and crumb softness to be maintained. Such performances cannot at present be obtained by using alternative industrial bread packaging materials, such as paper bags.

\section{CONCLUSIONS}

Our results show that some perforated OPP films can play an interesting role in modulating moisture changes inside the bread loaf. This effect, related to the water vapour permeability of the film and, therefore, to the characteristics of holes, may allow both crust crispness and crumb softness to be maintained.

Even if critical for bread quality, our data demonstrate that the macroscopic moisture exchanges from crumb to crust are not sufficient to justify the different staling kinetics induced by the packaging material. Since gel phases separated by aqueous interphases have been noted in bread,11 each OPP perforated film can probably induce a different water mobility, either within a given phase or at the interphases, influencing the formation of H-bonds. Particular and sophisticated approaches, such as NMR spectroscopy techniques, could help in understanding water mobility among protein and starch molecules.

\section{REFERENCES}

1. Pagani MA, Lucisano M, Mariotti M. Italian Bakery. In Bakery Products: Science and Technology, Hui YH (ed.). Blackwell: Ames, IA, 2006; 527-560.

2. Smith JP, Ooralkul B, Koersen WJ, Jackson ED, Lawrence RA. Food Microbiol. 1986; 3: 315-320.

3. Rodriguez M, Medina LM, Jordano R. Nahrung 2000; 44: 247-252.

4. Brown J. Advances in breadmaking technology. In Advances in Baking Technology, Kamel BS, Stauffer CE (eds). Blackie Academic \& Professional; London, 1993; 38-87.

5. Lee DS, Renault P. Packag. Technol. Sci. 1998; 11: 119-130.

6. Piergiovanni L, Limbo S, Riva M, Fava P. Food Addit. Contam. 2003; 20: 186-195.

7. American Association of Cereal Chemists. AACC Method 10-10B. AACC: St. Paul, MN, USA, 1995.

8. American Society for Testing and Materials. Standard Test Method E 96. ASTM: West Conshohocken, PA, USA, 1980.

9. American Association of Cereal Chemists. AACC Method 44-15A. AACC: St. Paul, MN, USA, 1995.

10. Piazza L, Masi P. Cereal Chem. 1995; 72: 320-325.

11. Schiraldi A, Fessas D. Mechanism of staling: an overview. In Bread Staling, Chinachoti P, Vodovotz Y (eds). CRC Press: Boca Raton, FL, 2001; 1-17. 